\title{
Educação e o paradigma do conflito: convergências para o exercício do confronto em meio à crise estrutural do capitalismo
}

Luis Fernando Novoa Garzon

\section{Resumo}

Educar é um ato de formação recíproca entre educador e educando. Um ato de dignificação recíproca. Dignidade que implica compreender o estar no mundo: homemhomem/homem-sociedade/sociedade-natureza. Isso quer dizer sentir-se parte do problema (desigualdade, racismo, depredação ambiental etc.) na sua devida proporção e responsabilidade e, especialmente, sentir-se parte da solução - a depender do grau de organização ou articulação do indivíduo e do segmento social em que esteja inserido. Com a irrupção de novos atores e dos movimentos sociais, especialmente a partir dos anos de 1980, vai-se construindo, no Brasil e em grande parte do mundo, uma esfera pública não estatal e não mercantil. Tanto a escola formal se viu recondicionada por essa nova esfera como também se multiplicaram as experiências não formais de escolarização nesse ínterim. O presente artigo, em diálogo com aportes específicos do pensamento crítico, procura avaliar de que forma os movimentos pela melhoria da educação formal e os movimentos que patrocinam experiências concretas de educação informal articulam ou podem articular agendas conjuntas.

\section{Palavras-chave}

Pedagogia do Conflito. Sociologia da Educação. Teoria Crítica. Sujeitos Coletivos.

1. Doutorando em Planejamento Urbano e Regional pela Universidade Federal do Rio de Janeiro, professor do Departamento de Ciências Sociais da Universidade Federal de Rondônia, membro da Rede Brasil sobre Instituições Financeiras Multilaterais, elabora pesquisas e intervenções no setor de infraestrutura no Brasil e no continente sul-americano, procurando desnudar a lógica oligopolista, predominante em seu planejamento. E-mail: I.novoa@uol.com.br. 


\title{
Education and the conflict paradigm: converging to the confrontation exercise in a structural crisis of capitalism
}

Luis Fernando Novoa Garzon*

\begin{abstract}
Educating is an act of reciprocal formation and dignification between educator and pupil. This dignity implies understanding how one is situated: man-man/man-society/ society/nature. This means feeling that one is part of the problem (inequality, racism, environmental degradation etc.) in its right proportion and responsibility, and especially feeling part of the solution - depending on the degree of one's (person or social segment) organization or articulation. Triggered by new social actors and social movements mainly active in the 80s, a new public sphere (non statal and non comercial) is building itself in Brazil and in great part of the world. Hence the formal school saw itself reconditioned by this new sphere as non-formal educational experiences were multiplied. The present paper seeks to, in dialogue with some specific grounds of critical thought, evaluate how the movements for the improvement of formal education and the movements which supported concrete non-formal educational experiences articulate or can articulate common agendas.
\end{abstract}

\section{Keywords}

Conflict Pedagogy. Educational Sociology. Critical Theory. Collective Subjects.

\footnotetext{
* Candidate for a doctor's degree in Urban and Regional Planning at the Federal University of Rio de Janeiro, professor at Social Department at the Federal University of Rondônia, Rede Brasil member about Multilateral Financial Institutions, elaborates researches and interventions on infrastructure area in Brazil and South-American continent, looking for figure out the oligopolistic logical, predominant on its planning. E-mail: I.novoa@uol.com. br.
} 


\section{Introdução}

Frente à sucessão de ondas de expansão e refluxo do capitalismo, em um quadro de crise crônica que incita novos ajustes de contas em desfavor dos setores populares e da faceta social residual dos Estados nacionais em que se insere a educação pública, creio ser pertinente revisitar autores que situaram a escola como espaço utópico ou de transgressão. Como os sistemas de ensino são resultantes da conjugação dos interesses predominantes em sociedades profundamente assimétricas e submetidas às hierarquizações da divisão internacional do trabalho, inevitável que se instalassem fortes pressões no sentido de sua remodelação.

Baseados em acordos rígidos entre frações do capital estrangeiro e nacional, setores médios e setores populares, os antigos marcos regulatórios estão sendo amplamente revistos. Os pactos passam, crescentemente, a ser definidos em marcos empresariais no bojo de redes econômicas globalizadas, sediadas no país ou não. Entra em vigor um novo processo decisório, protagonizado por grandes corporações imiscuídas nos Estados e sustentadas por eles, como bem demonstra o caso brasileiro.

A consecução das novas estratégias econômicas e políticas exige rearranjos constantes das alianças interempresariais em um país ou em um conjunto de países. Essas costuras e remendos das teias econômico-políticas, organizadas em blocos regionais e/ou áreas de livre comércio, irão requerer ampla mobilidade dos investimentos e máxima previsibilidade de retorno.

Nesse contexto, a educação vem sendo redesenhada em função das estritas "necessidades do mercado". Habilidades e competências são forjadas em conformidade com o padrão tecnológico-administrativo em que as empresas operam, ainda que tal padrão signifique um retrocesso do ponto de vista social, cultural e ambiental para a sociedade e a nação em seu conjunto. Perde-se, dessa forma, a mais elementar autonomia relativa do sistema de ensino para que ele possa reorientar o mercado ou, até mesmo, subsidiar uma eventual reorientação da sociedade de mercado. Não deveria ser concebível a redução da educação a uma atividade dedicada à formação de "capital humano", locução que evidencia a conversão do último termo pelo primeiro, visto que a educação-treinamento confere "utilidade" ao humano, e o que é pior, cada um por si, a investir em sua própria utilidade, no mínimo, suplementando-a.

A "empregabilidade" colocada como meta é uma demonstração de que, a despeito dos problemas serem socialmente produzidos, a tarefa de enfrentá-los é individualizada. Nesse modelo, indivíduos disciplinados supervisionam seuprópriodesempenho:aolidaremcomosriscos da autorreprovação e com as sequelas do não sucesso, agarram-se, submissos, às soluções préfabricadas em circulação no mundo corporativo.

As reformas no ensino impostas no bojo das reformas neoliberais - sintetizadas no chamado "Processo de Bolonha" ${ }^{2}$ - adotam como norte a "pedagogia das competências", que incorpora as necessidades particulares do mundo empresarial como se fossem necessidades universais e públicas. Por outro lado, a educação em distintos modos (formal e não formal) vai sendo redefinida na contramão por atores coletivos antes negados ou esquecidos. Pensar o espaço educacional como potencial matriz de novas formas sociais e qualificar, a partir dele, o exercício do confronto contrahegemônico é o que invoca o presente artigo.

2. A escolarização passa a ser propugnada como facilitadora da reestruturação produtiva, administrativa e dos saberes, em compasso com os ditames do vigente regime de acumulação flexível. A formalização da proposta se deu no âmbito das políticas liberalizantes dos setores de serviços na União Europeia (LEHER, 2010). 
A recente eclosão, nas principais cidades do país, de manifestações populares massivas por serviços públicos mais acessíveis e qualificados (com destaque para o transporte urbano, a saúde e a educação) torna ainda mais premente a disseminação de referenciais antissistêmicos no âmbito das práticas educacionais e/ou de formação. Procuro agrupar tais referenciais em torno da categoria "paradigma do conflito", vista, aqui, não como um corpo doutrinário homogêneo, mas como um enfoque que visibiliza as contradições sociais inerentes à sociedade capitalista e à própria educação. Assim como a classe trabalhadora somente se constitui e se reconhece na luta frontal contra a classe dominante (THOMPSON, 1987), a pedagogia do conflito $^{3}$ valoriza a experiência subjetiva das distintas formas de opressão e das distintas respostas coletivas que lhes são decorrentes.

\section{Marx e o Prometeu "desacorrentado"}

Para Marx, a escola não poderia ser senão o resultado de um determinado processo histórico, por isso não seria possível entendêla fora da totalidade social. As relações sociais de produção no capitalismo determinam a organização da produção e a distribuição de seus resultados. As duas classes fundamentais no capitalismo, burguesia e proletariado, constituem-se a partir da mais drástica divisão social dotrabalhojá ocorrida: entre os possuidores dos meios de produção e os possuidores de sua força de trabalho. O trabalhador alienado ou despossuído da produção e de seus frutos também é alienado da própria condição criadora da riqueza. Dessa forma, tanto o produto criado pelo homem lhe surge na frente como algo alheio ao seu esforço criativo, como também o mercado e a sociedade se assomam como entes autônomos, "naturais", aos quais por isso se submete. A criatura toma o lugar do criador. A escola alimentaria continuamente tal fetichismo, facilitando o encaixe disciplinado das classes e indivíduos nessa ordem social reificada ou "coisificada". A dominação capitalista prescinde de seu encobrimento, por isso o papel da superestrutura jurídica, política e religiosa - em que se inclui a escola - é promovê-lo sistematicamente. Em suma, a escola, no capitalismo, seria a sala de suplícios da Razão, que, de vocacionada a realizar todo potencial humano, converte-se em instrumento de sua mutilação. Uma ferramenta especializada na prática da desumanização.

As lutas de classes atravessariam, portanto, a escola, mas não se resolveriam nela. A trajetória da classe em si (classificada externamente) para a classe para si (construída na luta com as demais classes) seria demarcada antes de tudo pelas organizações independentes dos trabalhadores, o sindicato livre, o partido operário. Como outros intelectuais críticos do século XIX, que se sentem órfãos de um projeto de modernidade que se degradara em um novo regime de dominação ainda mais perverso, Marx projeta, nas ondas de protesto operário, a recondução da ideia da Revolução ao seu bom termo. As forças produtivas, desenvolvidas ao máximo com a Revolução Industrial, seriam a evidência do esplendor da razão humana, mas o Estado e o domínio burguês é que agora a acorrentavam. Prometeu, castigado por roubar o fogo do Olimpo e entregá-lo aos homens, seria, enfim, desacorrentado por uma Revolução proletária triunfante em escala internacional.

A escola, para Marx, só poderia cumprir função distinta depois de consolidada a Revolução e iniciada a transição do capitalismo ao comunismo. Nesse regime de transição, chamado de Socialismo, haveria um Governo da maioria contra a minoria e seria tempo

3. Provocado pela terceira tese de Marx contra Feuerbach acerca das condições subjetivas para o surgimento de agentes de transformação histórica, Gadotti (1980) indaga de que modo poderia se viabilizar uma educação que fosse transformadora de uma sociedade que a mantém e que por meio desta mesma educação se faz reproduzir. A resposta seria a "pedagogia do conflito". 
de equalização das condições de vida. A escola deveria contribuir, portanto, para o nivelamento do saber, da técnica e da cultura, pavimentando o caminho para o comunismo - a sociedade sem classes e sem Estado.

$\mathrm{Na}$ "nova escola", como designava Marx, a divisão entre trabalho manual e intelectual seria abolida. E do indivíduo parcial e parcelar do capitalismo nasceria o indivíduo integral, apto para compartilhar e multiplicar os infinitos benefícios da civilização (MARX; ENGELS, 2004).

\section{Gramsci, a escola e a "guerra de posição"}

A obra de Antônio Gramsci é um antídoto contra esquemas lineares e evolucionistas típicos do marxismo vulgar. É preciso compreender que os mais representativos escritos de Gramsci foram produzidos em um contexto de não realização da virtualidade revolucionária do biênio vermelho (1919-1920) na Itália e do advento do fascismo - e transcritos no cárcere. Frente a isso, de forma crítica e autocrítica, a sua pergunta foi: qual a razão da derrota da Revolução socialista no Ocidente?

Para o intento da resposta, fazia-se necessário reavaliar o conjunto das práticas revolucionárias nos países capitalistas de institucionalidade condensada sob a dominância imperialista, basicamente os países da Europa Ocidental. Por outro lado, era preciso fazer um ajuste de contas tanto com o determinismo histórico da II Internacional (que passaria a ser a referência dos partidos social-democratas como conhecemos hoje), quanto com posições voluntaristas e autonomistas, próprias do anarcossindicalismo.

É neste marco histórico e campo teóricoprático que podemos compreender e nos apropriar do aparato conceitual gramsciano. Comecemos pela visão ampliada do Estado, um inteiro articulado: parte coação, parte consenso. Esses dois momentos analíticos foram designados, respectivamente (na esteira de Hegel e Marx), de "Sociedade Política" e "Sociedade Civil". O Estado moderno se manifestaria na forma de uma "política-centauro", meio animal (força), meio homem (razão). A Sociedade Política é compreendida como o conjunto de organismos que exercem uma função coercitiva e de domínio direto nos campos jurídico, administrativo e militar. A Sociedade Civil é uma das formas da natureza estatal - essa interligação não pode ser esquecida. Nela, se dá a articulação institucional das ideologias e dos projetos classistas. É na Sociedade Civil que se inscreve a escola como: a) lugar de articulação de interesses estruturalmente desiguais; b) horizonte (meta) da racionalidade classista. Neste enfoque, o Estado deixa de ser um alvo concentrado, passível de ser assaltado em um rompante revolucionário. O Estado, ao se enraizar e se ramificar nas estruturas da sociedade civil, funcionaria como um sistema de trincheiras concêntricas. Os ataques e avanços precisam ser múltiplos e coordenados. Em contraposição à "Guerra de movimento", em que há um deslocamento de forças concentrado no espaço e no tempo, a "Guerra de posição" impõe o combate encarniçado ponto a ponto, trecho a trecho. As fortificações e trincheiras das democracias modernas fazem com que seja apenas "parcial" o elemento do movimento que constituía toda "guerra de assalto" (GRAMSCI, 1984, p. 73-75).

No cenário próprio dos países centrais, a burguesia, no processo de sua revolução, construiu seu Estado e ao mesmo tempo uma nova concepção de direito, uma nova ética; e tratou de obter ativamente um novo conformismo. A capacidade de assimilar a sociedade como um todo, ao nível cultural e econômico da burguesia, é o que Gramsci define como hegemonia. Em outras palavras, trata-se da desorganização ativa ou passiva dos projetos de outras classes: ativamente 
pelo convencimento, e passivamente pela repressão. A escola seria um espaço prioritário no exercício e consecução da primeira função.

Sendo tão crucial para a construção do convencimento, do estabelecimento de bases racionais e universais para os projetos particulares de dominação, a escola logicamente deve ser, na direção contrária, um front avançado para que se imponham constrangimentos e limites a esse mesmo processo. Ou seja, é lugar para o estabelecimento de contra-hegemonias, de bloqueio da hegemonia vigente. Na estratégia de ascensão das classes subalternas, seria indispensável, nas palavras de Gramsci (2002, p. 279):

[...] construir no invólucro da sociedade política, uma complexa e bem articulada sociedade civil, em que o simples indivíduo se governe por si, sem que por esse autogoverno entre em conflito com a sociedade política, pelo contrário, tornando-se-Ihe a continuação normal, o complemento orgânico.

Daí a relevância do papel dos intelectuais na organização da cultura ou da contracultura. Nesse último caso, o verdadeiro educador ensina ao suprimir o caráter iluminista, elitista, separado, abstrato de sua atividade intelectual. Intelectual orgânico das classes trabalhadoras é aquele que consegue expressar o conjunto dos interesses de sua classe em uma perspectiva universalizante, que demonstre a capacidade de direção de sua classe sobre o conjunto social. Este intelectual não seria forjado na escola formal, mas na escola da luta, nos comitês de base, na imprensa alternativa e, especialmente, no partido, que deve ser

o modo próprio de elaborar a categoria de intelectuais orgânicos, que se formam assim diretamente no campo político e filosófico, e já não mais no campo da técnica produtiva. (GRAMSCI, 1982, p. 14).

\section{Teoria da Reprodução (Bourdieu e Passeron)}

Foi no Centro de Sociologia da Escola Prática de Altos Estudos (EPHE), em Paris, entre 1964 e 1970, que Pierre Bourdieu e Jean Claude Passeron levaram a cabo, de forma sistemática, suas pesquisas sobre o ensino superior e o papel reprodutor da escola. Reciprocidades e continuidades entre a escola e o ordenamento socioeconômico são, então, nomeadas, identificadas e enfatizadas.

A imersão em distintos universos materiais e simbólicos, próprios de cada classe, implica em trajetórias escolares e em resultados de escolarização igualmente diferenciados. Resultados estes que convalidam e certificam a estratificação social assimétrica prévia, normalizando-a. O processo educativo é, portanto, constituinte do indivíduo e da sua "interindividualidade" expressa no grupo social imediato. A educação conformaria o habitus, ou seja, um conjunto de práticas, valores e expectativas internalizadas.

Bourdieu vai além da identificação do lugar das classes na estrutura de produção ao priorizar a interrelação entre elas em contextos em que se configuram distinções de renda e também distinções simbólicas, de linguagem e de prestígio. Para fins de visualização, Bourdieu decompôs esse conjunto em três tipos de capital: econômico, cultural e social.

O capital econômico, propriamente dito, envolveria indicadores de renda e patrimônio, levando em conta o número de filhos por família e investimentos prévios na criança (como poupanças e seguros) no intuito de garantir a reprodução do patamar socioeconômico obtido ou sua progressão. Em sentido amplo, o capital cultural representaria o acúmulo específico de referências de informação, de gostos, valores, símbolos e de como tal acúmulo se converteria 
em uma familiaridade com um determinado universo cultural. Já o capital social, sob uma perspectiva integralizante, espelharia o agregado de relações do indivíduo em gradações de intensidade e de vínculo/oposição, permeando a composição das duas outras formas de capital.

No conhecido texto "A Reprodução", Bourdieu e Passeron (1975) concluem que a função social da escola, em última instância, é dissimular os mecanismos ideológicos de reprodução das condições de manutenção da ordem social. Ou seja, transmitir conhecimentos, hábitos, visões de mundo e posturas que positivem a ordem social.

Essa transmissão vertical só pode ser entendida como resultante de um embate entre diversos projetos dominantes e, depois, nos marcos de relações de subordinação ou de hegemonia sobre grupos ou classes sociais subalternos na sociedade. A hipótese central da Teoria da Reprodução não pode ser reduzida a uma classificação da funcionalidade do sistema de ensino. A questão é demonstrar como essa funcionalidade é recoberta pelo discurso da autonomia, da competência e do mérito. A autonomia relativa da escola frente aos requisitos estruturais dos meios de produção seria a própria condição para a reprodução legítima, isto é, estável e eficiente desses mesmos requisitos.

A violência patrocinada pela escola e na escola se estabelece veladamente por meio de artifícios indiretos e subliminares, daí, para Bourdieu e Passeron (1975, p. 17), a escola ser, por excelência, lugar de "poder de violência simbólica". Toda forma de dominaçãoélida como administração e consentimento; significados, portanto, pré-fabricados e impostos, relações de força disfarçadas, naturalizadas, legítimas desde sempre. A mutilação das subjetivações possíveis é sutil e sistematicamente impingida. A violência simbólica, para Bourdieu (1999), é aquela que se exerce nas formas, ou seja, de tudo o que pode e deve ser dizível e inteligível, "pondo as formas":
Pôr as formas é dar a uma ação ou a um discurso a forma reconhecida como conveniente, legítima. A força da forma, vis formae na expressão dos antigos, é esse poder simbólico que permite à força exercer-se plenamente fazendo-se reconhecer, aprovar e aceitar, por mostrar-se sob as aparências da universalidade. (BORDIEU, 1999, p. 109).

A violência simbólica cristaliza-se na conformação do habitus, traços adquiridos durante a formação psicossocial que conformam suas predisposições de sentir e agir. Em outras palavras, o habitus é a socialização de cada um de nós em contextos determinados, a interiorização da exterioridade circundante. O que pode ser espaço de liberdade, libertação, identificação e autonomização também pode ser espaço de proscrição, classificação e enquadramento. O fracasso e o êxito na escola seriam definidos pela prévia hierarquização dos padrões de habitus dominantes e/ou aceitáveis na sociedade.

Ao habitus primário desenvolvido no ambiente familiar, da alteridade imediatamente significativa, soma-se o habitus secundário, forjado na escola e em grupos de referência extrafamiliares. As duas formas de habitus "funcionam como princípios geradores (a um só tempo diferenciadores e unificadores), das estratégias dos agentes" (PEREIRA; CATANI, 2002, p. 111). Isso porque se supõe um "sentido do jogo", ainda que tal sentido não seja consciente; jogo em que cada agente busca se afirmar e se posicionar a partir de lugares distintos.

A escola é um palco recorrente da explicitação deste "sentido do jogo" (NOGUEIRA, 1997). As classes sociais, em sua constituição posicional e conflituosa, apresentam distintas estratégias frente à escola. Os setores médios apostam todas as fichas nela como recurso quase exclusivo de ascensão social. Abaixo, na escala social, os setores populares colocam-se de forma arredia e ambígua frente ao sistema escolar que irá reprovar as posições sociais "inferiores" de origem. Acima, os setores 
privilegiados, em paradoxal paralelismo, também tendem a ser indiferentes aos "méritos escolares" e atentos apenas a um investimento escolar adequado aos investimentos financeiros já empenhados. O retorno almejado é a chancela para as posições de topo já adquiridas.

Essas estratégias não surgem nem se expressam isoladamente, mas relacional e posicionalmente. Os setores populares, não possuindo o mesmo tipo de capital cultural dos demais setores, procuram vacinar-se contra a reiteração do fracasso social em fracasso escolar. Os setores médios, olhando para o fosso social abaixo de si, lutam desesperadamente, e com as armas de que dispõem, para se dependurar em funções acessórias às funções de comando, controladas pelos setores privilegiados. Estes últimos confirmam sua posição de prestígio na razão direta de seu distanciamento dos setores que cobiçam ou contestam seu padrão de vida.

A "topologia social" oferecida por Bourdieu pode ser refinada incluindo-se outras variáveis, adicionais ao peso relativo dos capitais particulares (econômico, social e cultural) de cada classe. Um exemplo seriam as trajetórias (ascendentes ou descendentes) dos grupos, independentemente da classe social. Muitas vezes, as referências para a formação do habitus podem permear as fronteiras das classes, como se pode observar nas estratégias de ascensão adotadas por grupos de imigrantes ou emigrantes.

Autores do mesmo campo da pedagogia crítica enfatizam ainda que, além de desmascarar os pressupostos da pedagogia de matriz liberal ou conservadora (igualdade de oportunidades e/ou neutralidade), seria preciso identificar as contraestratégias dos grupos subordinados, sobre como, sob intenso bombardeio ideológico, conseguem elaborar contradiscursos e contra-hegemonias no interior do aparelho escolar. Abordagens reprodutivistas grosseiras, esquemáticas e/ ou descritivas passam ao largo desse esforço:
A ideia aqui é que as ideologias dominantes não são simplesmente transmitidas pela escola, nem são implementadas no vazio. Pelo contrário, com frequência precisam enfrentar encarniçada resistência da parte de professores, alunos e pais e, portanto, para obterem êxito, precisam reprimir a produção de contra-ideologias. Por isso mesmo, as escolas não são instituições estáticas que reproduzem a ideologia dominante, são também agentes ativos nessa construção. (GIROUX, 1995, p. 124).

Assim, se há o claro propósito de aprofundamento do desmonte da Nação e do Cidadão para que vigore em seu lugar nada mais que Mercado e Consumidor, o lócus estratégico para essa formação e legitimação é a escola. Crucial, pois, dimensionar o seu papel na distribuição de poder, renda e prestígio em seus devidos lugares; comparar as escolas temáticas, bilíngues e corporativas das elites abastadas com a escola pública sucateada. A que faz de conta para o "público" ficar na sua, no vazio convidativo a qualquer sacrifício para galgar qualquer degrau rumo ao andar de cima. O monopólio da indústria da miséria não é um monopólio qualquer. As escolas públicas se tornam espaços de assistência e controle social mínimo.

O projeto transparece e se visibiliza na escola e na antiescola. Nos cheios e nos vazios, lá estão as arenas que procuram sancionar as linhas de corte, as assimetrias de poder e de tecnologia. Concomitantemente, os lugares de aprendizado na mão e na contramão, em que podemos seguir lutando para que exerça seu papel de humanização, de socialização e de subjetivação do ser humano.

\section{A Sociologia das ausências}

O ausente é o inominável, porque sendo nominável colocaria em questão o sistema classificador que exclui ou hierarquiza. A sociologia das ausências e, consequentemente, 
a pedagogia das ausências, procura colocar em cena o que foi sorrateira ou abertamente apagado e, assim, nominar o inominável.

O ideário dominante exclui do concebível tudo o que não couber na narrativa da ordem; é um minucioso controle sobre o que pode ou não se sedimentar como memória coletiva. Boaventura de Sousa Santos (2002) costuma dizer que o inexistente é intensivamente produzido enquanto tal. O futuro prenhe do novo, que insiste em se entranhar no tempo/espaço, precisa ser incessantemente socavado. Por isso a ausência, a negação, a repressão e a exploração são necessariamente uma árdua construção social e não um quadro imóvel e consumado.

O convite é ler o mundo pelo anverso, pelo não dito, pelas lacunas. Contra quem e sobre quem se ergueu a sociedade industrial? Onde e em que posição estão os povos colonizados, etnias, operários, camponeses mulheres, biomas e culturas? Onde se refugiaram seus herdeiros? Como ouvir o eco de suas vozes redivivas? Essa acuidade/sensibilidade - que deve muito à visão de Walter Benjamin de colher as experiências históricas a "contrapelo" - procura "transformar objetos impossíveis em possíveis e com base neles transformar as ausências em presenças" (SANTOS, 2002, p. 246).

A tarefa é encontrar as concepções mesmas dos vácuos, decompor o processo de esvaziamento com suas quantidades absolutas mensuráveis interpretáveis, sua invariância das relaçõesdedeterminação, suasregularidadesmais que previstas, impostas. Quem está autorizado a ditar o futuro como um clone, andróide, uma sucessão automática e "maquínica" de ciclos tecnológicos sempre "superiores"? Nesse tempo vazio, nesse "não lugar" onipresente, ser chique é ser planejadamente fútil, ou seja, estar "em dia" com o padrão de consumo.

$\mathrm{O}$ indivíduo soberano e afluente, meta do liberalismo, na verdade não passa de uma estéril prima donna administrando uma combinação "originalíssima" de estilos de vida e respectivas marcas, escolhidos no shopping center mais próximo: naturalmente o lugar a que todos devem afluir para poderem escolher e atualizar o que são e como devem ser. Espelhos distorcidos por todas as partes capturam de nós os fragmentos que convêm. Assim, nos vemos neles, inteirados e pontilhados a partir de expectativas já construídas. A vitrine - sempre mais viva que tudo ao redor, consumidores e seus gostos natimortos diz quem comanda. Não são os marqueteiros dedicados à venda final que manipulam, eles só fazem sinalizar atalhos, facilitando a captura e fidelização de mais um nicho de mercado. A tarefa do marketing, a de pensar o campo de influência e o escopo de identificação de uma mercadoria, instalou-se nos centros decisórios últimos. Serviços e produtos são concebidos para serem veículos de poder e controle. Tanto mais somos rebocados e tripulados pelas mercadorias quanto mais nos impregnamos delas e as utilizamos como mediadoras exclusivas de nossas emoções.

Uma população assim, que perdeu a capacidade de produzir suas mediações culturais, torna-se refém daqueles que controlam os instrumentos de socialização e de autointerpretação dos indivíduos.

Contra esse enorme desperdício de experiência, é preciso estar sempre de prontidão para o resgate e para a reoriginalização, não de produtos, mas de contextos culturais. Sempre atentos às simultaneidades oclusas, às ordens por meio de flutuações, à história aberta, à obra aberta (SANTOS, 2000).

A reinvenção da emancipação, nesses termos, pressupõe a repolitização da vida coletiva. Há questão mais precedente que a de recuperar a noção de responsabilidade coletiva pelo futuro frente às micro-responsabilidades emanadas pelos grupos de referência mais imediatos? O cenário de crise ecológica e financeira global é convidativo para esse reaprendizado cívico-social, mas, ao mesmo 
tempo, irá proporcionar um novo conjunto de armadilhas ideológicas e operativas do mercado.

A batalha de primeira e última instância é no plano das subjetividades. É preciso sinalizar para formas de bem viver e de prazer que saiam da esfera do consumo hedonista e/ou escapista. Bem viver é celebrar a consciência do usufruto, a trajetória intensamente compartilhada, é o reencantamento das práticas sociais das comunidades e neocomunidades.

Os campos de invisibilidade são novos campos de concentração que dependem de sua invisibilidade para os serem. Essa subtração do mundo, e de nós mesmos, merece e pode ser estancada. O olhar anverso das ausências nos obriga a continuar a repensar o caminho.

\section{Freire e o aprendizado da libertação}

Aos esfarrapados do mundo e aos que neles se descobrem e, assim descobrindo-se, com eles sofrem, mas, sobretudo, com eles lutam. (FREIRE, 2003).

No país que continua com uma das piores distribuições de renda do mundo, administrar a questão social significa a diferença entre manter ou não manter poder. A história das classes dominantes brasileiras pode ser contada por meio dos massacres patrocinados contra a população indígena, negra, mestiça e pobre. Tamanha desigualdade só se manteve até aqui com a imposição de uma eficiente gestão da violência - física e simbólica. O incessante zunir da chibata ainda demarca a distância entre a privação e o privilégio. A espada sempre desembainhada mantém a distância, o povo por inimigo, os canhões voltados para dentro. Com os corpos destrinchados, o país foi se fazendo inteiro - e continua.

O conjunto dos oprimidos, vendo-se enquanto tais, sob o jugo da opressão e de forma coletiva, gabaritam-se como sujeitos de sua própria libertação. Esse seria o papel da pedagogia libertadora, segundo Paulo Freire (2003): ao invés da transmissão e memorização dos códigos da submissão, o aprender da prática refletida, da vida e da história posta em cheque pelas próprias classes populares.

Dos campos e das fábricas não deixavam de ressoar os rumores da senzala. A modernização do capitalismo brasileiro não se deu apesar das relações pré-capitalistas, mas por causa delas, em uma combinação perversa entre formas arcaicas e modernas que otimizam a exploração da mão-de-obra. Duplamente oprimidos pela falta do "progresso" e pelo tipo do "progresso" oferecido, os setores populares, ao criarem novas formas de organização no final dos anos de 1970, sublimaram sua própria experiência de opressão em uma oportunidade de exercício e de aprendizagem de sua libertação. A obra mestra de Paulo Freire, "Pedagogia do Oprimido", não casualmente é dedicada aos "esfarrapados", esses "homens, mulheres, meninos desesperançados, mortos em vida, sobras de gente" (FREIRE, 2003, p. 29); os "condenados da terra", então, passam a julgar os que os condenaram historicamente.

O que cabe na classe trabalhadora e o que se esparrama dela, em todas as suas matizes, categorias, etnicidades e gêneros, conflui para o "oprimido". O ponto final do acúmulo das contradições pode virar ponto de partida com base em uma releitura que tem como eixo o resgate da pessoa humana e dos coletivos sociais negados. Essa libertação generosa livrava inclusive o dominador, também alienado e desumanizado em seu papel instrumentalizador.

A conscientização não se consuma no plano mental ou teórico. Não basta alterar o sinal da pedagogia conservadora para a pedagogia crítica, se de uma forma ou outra ela continua sendo bancária, vertical, limitada à transmissão e à memorização:

Essa concepção bancária implica, além dos interesses referidos, outros aspectos 
que envolvem sua visão falsa dos homens. Aspectos ora explicitados, ora não, em sua prática. Sugere uma dicotomia inexistente homens-mundo. Homens simplesmente no mundo e não com o mundo e com os outros. Homens expectadores e não recriadores do mundo. (FREIRE, 2003, p. 62).

Para tanto, o pré-requisito seria a universalização e a qualificação do ensino público com uma pedagogia libertadora voltada para a construção de novos sujeitos e para a transformação da coletividade. Por isso mesmo é que, ao longo da história do país, o sistema público de ensino foi sistematicamente sabotado. Tal foi a invariável postura preventiva dos círculos de poder mais concentrados no intuito de selar, represar e condicionar o destino comum de nossa gente.

A pedagogia freireana foi aposta de longo prazo, generosamente sistematizada passo a passo para ser da grande maioria. Aposta em um Brasil popular: sua recriação seria de baixo para cima com democratização de renda, poder e cultura. A eleição de um ex-líder sindical, dirigente de um ex-partido de esquerda - no qual desaguaram a maioria dos movimentos e organizações anticapitalistas e anti-imperialistas, ou simplesmente antipatronais, nos anos de 1980 e 1990 - teve um efeito reverso na perspectiva de uma alternativa antissistêmica. A que serviram e a quem têm servido a força e a legitimidade social adquiridas no conjunto das lutas contra a ditadura e contra as injustiças? Sintomático que sejam Lula, Dilma e o Partido dos Trabalhadores que tenham que presidir o processo de consolidação da democracia representativa em uma formação capitalista em ascensão regional e mundial.

Há uma combinação de renúncias no pacto que elegeu Lula em 2002. Ao final, percebeu-se que as renúncias dos de cima são, na prática, hedges (seguros) antitransformação e que ainda podem proporcionar mais rápido fatiamento e domesticação dos mercados de trabalho.
É nesse quadro de derrota histórica que se institucionaliza e se banaliza a contribuição de Paulo Freire. O discurso crítico é replicado e esvaziado para, assim, poder representar de forma minimamente fidedigna o diálogo em que só há imposição da lei do mercado. É preciso, então, desconstruir, cotidianamente, essa visão falseadora e edulcorante da realidade. O olhar do expectador prende-se à tela-cabresto colocada à sua frente. Quem reparar além e por detrás da projeção domesticadora deixa de ser espectador.

Paulo Freire continua nos incitando ao encontro das dobras clandestinas da realidade. Lá estão as mídias, organizações e linguagens alternativas a enfrentar os grandes moinhos da mistificação. Os novos movimentos de caráter político-cultural-artístico, o enraizamento das lutas fundadas na concepção de gênero, etnia, sensibilidade e postura; a experiência de redes de resistência e projetos de economia solidária. Nas ruas e nas ocupações aquilata-se a vontade arrebatadora de milhões de fazer tudo de novo e de outro jeito.

\section{Considerações Finais}

A "radicalização da democracia" hoje passa ao largo da institucionalidade liberal burguesa, pois ela foi, em grande parte, esvaziada, inclusive de sua função retórica. O deslocamento permanente do capitalismo (setorial, organizativo, territorial) vai tornando ilegíveis as concatenações, as costuras e as referências identitárias coletivas. Resgatar as condições de legibilidade dos campos de força, apreender os deslocamentos em curso é condição para reinventarmos a escala da representação e da participação em campo insubmisso ao mundo empresarial-financeiro e seus braços políticos (a grande mídia, as associações empresariais e os partidos da ordem).

Deteriorada e capturada a esfera pública, precisamos instaurar uma contraesfera pública que passe a disputar a agenda da sociedade 
política com legitimidade e visibilidade. Os caminhos de mão única não são mais tolerados sem resistência. A combinação da democracia representativa com a democracia participativa tem sido avaliada, até mesmo pelos donos do poder, como concessão necessária para conferir mínima efetividade às decisões. Em tempos de insurgência, oscilam entre a promessa de reformas institucionais e a repressão aberta contra aqueles que não quiserem restringir sua atuação ao esquadro "autorizado" de organização e de expressão populares.

A alardeada "crise de representação" por que passa o Brasil não se reduz, portanto a uma falha técnica de seu sistema político, é antes uma crise de hegemonia em que se expressa a incapacidade do bloco no poder de obter consentimento dos dominados. Não casualmente, os protagonistas das "jornadas de junho" foram os segmentos da juventude que foram "socializados" em um mercado de trabalho e em um sistema de ensino altamente precarizados. No âmbito da escola formal, o horizonte continua sendo o controle social do processo decisório educacional, desde a implementação das diretrizes nacionais à gestão compartilhada das unidades de ensino. Essa frente de luta, historicamente, esteve nas mãos das representações docentes e discentes. As políticas de fragmentação e de desmanche dos serviços públicos afetaram duramente essas formas clássicas de representação e, devido a isso, frestas difusas e transversais têm surgido. Iniciativas espontâneas e fóruns de discussão têm procurado criar novos campos de incidência e de enfrentamento.

Faz-se necessário aprofundar e qualificar a participação popular "permitida" e conquistar poder deliberativo para conselhos com representação proporcional. Ao mesmo tempo, é crucial que se mobilize a base social em torno de linhas programáticas democratizantes e socializantes de modo que cada luta social possa ser traduzida em termos institucionais e ético-políticos, dando vazão a experiências embrionárias de um outro poder.

No âmbito informal, multiplicam-se projetos de educação popular acompanhando a diversidade dos instrumentos de luta construídos historicamente pelos setores populares, no calor da conjuntura de agudização da crise capitalista. O contexto e a circunstância das lutas sociais, de leitura e de interferência direta no mundo, fazem dos movimentos, campanhas e manifestações, processos formativo-pedagógicos em si, que por sua vez desdobram-se em processos deliberados de autoentendimento e de posicionamento. As políticas específicas de formação promovidas pelos movimentos e coletivos procuram otimizar as oportunidades já existentes do aprender-vivendo em seu cotidiano do conflito, sistematizando históricos, conteúdos e testemunhos que reforçam o ponto de partida mobilizador.

O desafio é fazer comunicar entre si a diversidade desses coletivos outsiders, forjados mais na luta direta que na herança de tradições organizativas e discursos autorreferentes. A construção de um amplo e variado movimento de massas capaz de retratar todas as nuances da resistência popular aos planos e ações do grande empresariado e do Estado, em sua variante social-liberal, no Brasil, requer engenhosidade institucional e acurada visão estratégica. Cabe aos educadores-educandos críticos proporcionar a devida perspectiva histórica aos espaços de autonomia conquistados nos processos de mobilização que se intensificam. 


\section{Referências}

BOURDIEU, P. As coisas ditas. São Paulo: Brasiliense, 1999.

BOURDIEU, P.; PASSERON, J. C. A reprodução: elementos para uma teoria do sistema de ensino. Rio de Janeiro: J. Zahar, 1975.

PEREIRA, G. R. de M.; CATANI, A. M. Espaço social e espaço simbólico: introdução a uma topologia social. Perspectiva, Florianópolis, v. 20, p. 107-120, 2002.

FREIRE, P. Pedagogia do oprimido. 36. ed. Rio de Janeiro: Paz e Terra, 2003.

GADOTTI, M. Educação e poder: introdução à pedagogia do conflito. São Paulo: Cortez, 1980.

GIROUX, H. A teoría y resistencia en educación. México: Siglo XXI, 1995.

GRAMSCI, A. Cadernos do cárcere. Rio de Janeiro: Civilização Brasileira, 2002.

GRAMSCI, A. Maquiavel, o Estado e a Política. Rio de Janeiro: Civilização Brasileira, 1984.

GRAMSCl, A. Os intelectuais e a organização da cultura. Rio de Janeiro: Civilização Brasileira, 1982.

LEHER, R. Uma universidade com o campo das humanidades estilhaçado: cenário futuro da UFRJ? Revista do CFCH-UFJ, Rio de Janeiro, v. 1, n. 1, p. 34-52, 2010.

MARX, K.; ENGELS, F. Textos sobre educação e ensino. São Paulo: Centauro, 2004.

NOGUEIRA, M. A. Convertidos e oblatos - um exame da relação classes médias/escola na obra de Pierre Bourdieu. Educação, Sociedade e Culturas, Porto, n. 7, p. 109-129, 1997.

SANTOS, B. S. A crítica da razão indolente: contra o desperdício da experiência. São Paulo: Cortez, 2000.

SANTOS, B. S. Para uma sociologia das ausências e das emergências. Revista Crítica de Ciências Sociais, Lisboa, n. 63, p. 237-280, 2002.

THOMPSON. E. P. A formação da classe operária inglesa. São Paulo: Paz e Terra. 1987

Submetido em 10 de março de 2013.

Aprovado em 11 de junho de 2013. 